Int. J. Dev. Biol. 48: 441-449 (2004)

\title{
Collective cell migration in morphogenesis and cancer
}

\author{
PETER FRIEDL*, YAEL HEGERFELDT and MIRIAM TUSCH \\ Molecular Cell Dynamics Laboratory, Rudolf-Virchow Center, DFG Research Center for Experimental Biomedicine \\ and Department of Dermatology, University of Würzburg, Germany
}

\begin{abstract}
The movement of cells that maintain cell-cell junctions yet protrude along or within tissues is an important mechanism for cell positioning in morphogenesis, tissue repair and cancer. Collective cell migration shares similarities but also important differences to individually migrating cells. Coherent groups of cells are arranged and held together by cell-cell adhesion molecules, including cadherins, integrins, ALCAM and NCAM. Integrins of the $\beta 1$ and $\beta 3$ families further provide polarized interactions with the extracellular tissue environment, while matrix-degrading proteases become focalized to substrate contacts to widen tissue space for the advancing cell mass. By generating one functional unit, in contrast to individual cell migration, collective migration provides the active and passive translocation of mobile and non-mobile cells, respectively. This review highlights cellular and molecular principles of collective migration in the context of morphogenic tissue patterning and tumor cell invasion.
\end{abstract}

KEY WORDS: cell migration, epithelial cell, collagen, integrin, MMP, cadherin

\section{Introduction}

Cell migration is commonly understood as the movement of individual cells that undergo polarized extension-contraction cycles coupled with adhesion to and deadhesion from the surrounding substrate. Besides this well established mode of cell migration, detailed knowledge obtained over the past 20 years suggests that at least one additional major principle is relevant to cell translocation in or on tissues: the movement of cell groups, sheets, or strands consisting of multiple cells that are mobile yet simultaneously connected by cell-cell junctions (Nabeshima et al. 1999, Friedl 2004). This migration mode, although ubiquitous in development, tissue repair and tumor invasion, has been largely unexplored and still awaits systematic classification. This review will summarize the many biological facets of collective migration from a historical perspective and attempt to integrate cellular and molecular data from various in vitro and in vivo models in morphogenesis and cancer.

\section{Historical background}

The first description of mobile cells, delivered by Virchow in 1863 , shows the movement of individual leukocytes isolated from canulated ductus thoracicus lymph (Virchow 1863). In the late $19^{\text {th }}$ and early $20^{\text {th }}$ century, independent indirect observations from fixed tissue samples additionally suggested that, besides single cells, groups of cells might contribute to epithelial regen- eration during wound repair (Barfurth 1891, Eycleshymer 1907). Histological time series from the chick embryo allowed the description of mesenchymal cell clusters that appear to move collectively to form the heart primordia (DeHaan 1963). The first formal proof for actual collective migration in mammalian cells stems from the culture of epithelial chick embryo cells in 2D liquid culture. Sequential photographic imaging showed that epithelial sheets move across the substrate by membrane ruffling at the free edge only, while cell-cell junctions within the moving cell group remain intact (Vaughan and Trinkaus 1966). Indirect evidence subsequently suggested, that invasive SV109 carcinoma cells penetrate the chorioallantoic membrane while maintaining cell-cell junctions and form solid cell nests in the interstitial stroma (Easty 1974). The videomicroscopic description of a collective pulling mechanism via front-rear asymmetry stems from the cluster migration model of Gordon-Kosswig melanoma cells explanted from Xiphophorus maculates. In these clusters, the adhesion site to the underlying glass support resides some micrometer behind the anterior ruffling front, as visualized by interference reflection microscopy of the multicellular leading edge (Kolega 1981), which is known as the region of focal adhesions or focal

Abbreviations used in this paper: 2D, two-dimensional; 3D, three-dimensional; ALCAM, activated leukocyte adhesion molecule; MMP, matrix metalloproteinase; MT-MMP, membrane-type MMP; NCAM, neural cell adhesion molecule; ROCK, Rho-associated serine/threonine kinase substrate; uPA, urokinase-type plasminogen activator; uPAR, receptor of uPA.

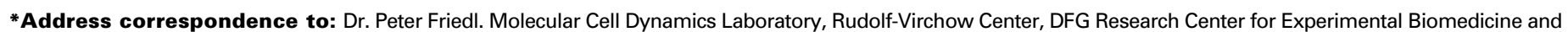
Department of Dermatology, University of Würzburg, Josef-Schneider Str. 2, 97080 Würzburg, Germany. e-mail: peter.fr@mail.uni-wuerzburg.de
} 
contacts. Dynamic image analysis further suggested that one or up to several free edges in one cluster may generate outward traction, yet net migration of the cell group follows the most dominant leading edge or an integrated vector, resulting in high directional persistence frequently close to a straight line (Kolega 1981). The forces generated by cell clusters appear to be higher than those used by individual cells, as estimated from comparative measurements of the number and size of focal contacts (Kolega 1982). Similar cluster polarity and migratory persistence were confirmed for cell groups and sheets that spontaneously develop from human cancer explants invading into 3D collagen lattices (Friedl et al. 1995) and well-differentiated hepatocellular carcinoma cells during their culture on fibronectin-coated surfaces (Nabeshima et al. 1995).

The concept of collective migration in higher mammals is supported by studies from the slime mold Dictyostelium discoideum. After conflux of amoeboid single cells and transition to the multicellular organism, a mobile slug of up to $10^{5}$ cells arises and generates collective migration over the substratum (Palsson and Othmer 2000). In contrast to mammalian cells in interstitial tissues, the slug moves through diverse biomaterials of the living and non-living nature, such as soil, mud and biological debris, so far leaving the molecular nature of adhesive interactions towards those substrata unresolved.

In conjunction, the above referred findings have established basic cellular principles of collective migration as one variant of eucaryotic cell translocation. The motor action is generated by cytoskeletal activity of several cells at free edges to substrate that "lead" and pull the other cells forward. The bulk of the group becomes dragged behind by cell-cell junctions and follows by a putative passively gliding mechanism.

\section{Terminology}

A variety of terms describe certain forms of collective cell movement, as derived from different experimental model systems (Table 1). Even though these terms reflect the wide range of shapes, dynamics and transition variants of this particular migration type, it appears important to integrate those processes into common principles, where possible. In this review, the term "collective migration" is used to describe the migration of cells that remain connected by cell-cell junctions during their movement, irrespective of previously used model-dependent designations.

\section{Models to study collective migration}

Several experimental systems exist to either directly or indirectly study collective migration. The most direct observations on collective cell migration in vitroand in vivo have been obtained by time-lapse microscopy in combination with subsequent sample fixation and immunofluorescence imaging. The culture conditions comprise 2D and 3D culture models in vitroas well as direct in vivo imaging of morphogenic movement in early, thus transparent embryos.

\section{Cells}

For in vitrostudies, collective migration requires the use of cell lines that retain a high degree of cell-cell as well as cell-substrate adhesiveness. Non-neoplastic epithelial cell lines express cadherins and other cell-cell adhesion receptors and constitutively develop sheet-like 'epithelial' migration behavior in vitro. In contrast, many available cancer cell lines lack stringent cell-cell junctions and retain a preference for single cell behavior, i.e. the growth and migration as individual cells. A useful strategy to capture collective migration in tumor cells is the primary culture of explants from embryonic or neoplastic tissue in vitrofor long-term imaging (Kolega 1981, Friedl et al. 1995).

\section{$2 D$ in vitro assays}

The most simple approach to study collective migration is the migration of cell monolayers towards a cell-free region across a 2D culture dish. A popular model is the so-called "wound scratch assay": an artificial wound by mechanically removing cells from a central region is generated by a needle scratch across a confluent monolayer of epithelial or mesenchymal cells (keratinocytes, fibroblasts) (Vaughan and Trinkaus 1966, Nobes and Hall 1999). The ensuing migration of the multicellular front then mimics epithelial defect closure (Grose et al. 2002). A modification of this assay is the seeding of cell clumps on 2D substrate which yields collective attachment and outward spreading of a radiary lamella followed by multicellular migration of the cell sheet (Nabeshima et al. 1998).

\section{$3 D$ in vitro assays}

If multicellular aggregates or tissue explants are integrated into 3D extracellular matrix, such as a 3D collagen lattice or thick reconstituted basement membrane (matrigel), individual cells but

TABLE 1

\section{TERMS USED FOR COLLECTIVE MIGRATION PROCESSES IN DIFFERENT MODELS}

\begin{tabular}{|c|c|c|c|}
\hline Term & Cell type & Environment & Ref. \\
\hline Migrating cell sheet & Embryonic keratinocytes & 2D glass cover slip & (Vaughan and Trinkaus 1966) \\
\hline Migrating cell cluster & Fish melanoma cells & 2D glass cover slip & (Kolega 1981) \\
\hline Migrating cell cluster & Epithelial and mesenchymal cancer explants & 3D collagen lattice & (Friedl et al. 1995, Hegerfeldt et al. 2002) \\
\hline Cohort migration & Adenocarcinoma cells & 2D fibronectin or gelatin coated surface & (Nabeshima et al. 2000, Nabeshima et al. 1995) \\
\hline Collective migration & Multicellular state of Dictyostelium discoideum & 2D surfaces & (Palsson and Othmer 2000) \\
\hline Branching morphogenesis; tubulogenesis & Epithelial tubular cells, i.e. mammary or bronchial epithelium & $3 \mathrm{D}$ gelatin or collagen matrices & (Zegers et al. 2003) \\
\hline Migrating cell cluster & $\begin{array}{l}\text { Undifferentiated cells in the blastoderm } \\
\text { (noninvoluting endocytic marginal cells) }\end{array}$ & Zebrafish (in vivo) & (Cooper and D'Amico 1996) \\
\hline Cluster migration & Slow border cells & Drosophila ovary & (Montell et al. 1992) \\
\hline Bulk movement & epithelial cells at the rims of the optic and thyroid placodes & Chick embryo & (Hilfer et al. 1990) \\
\hline
\end{tabular}



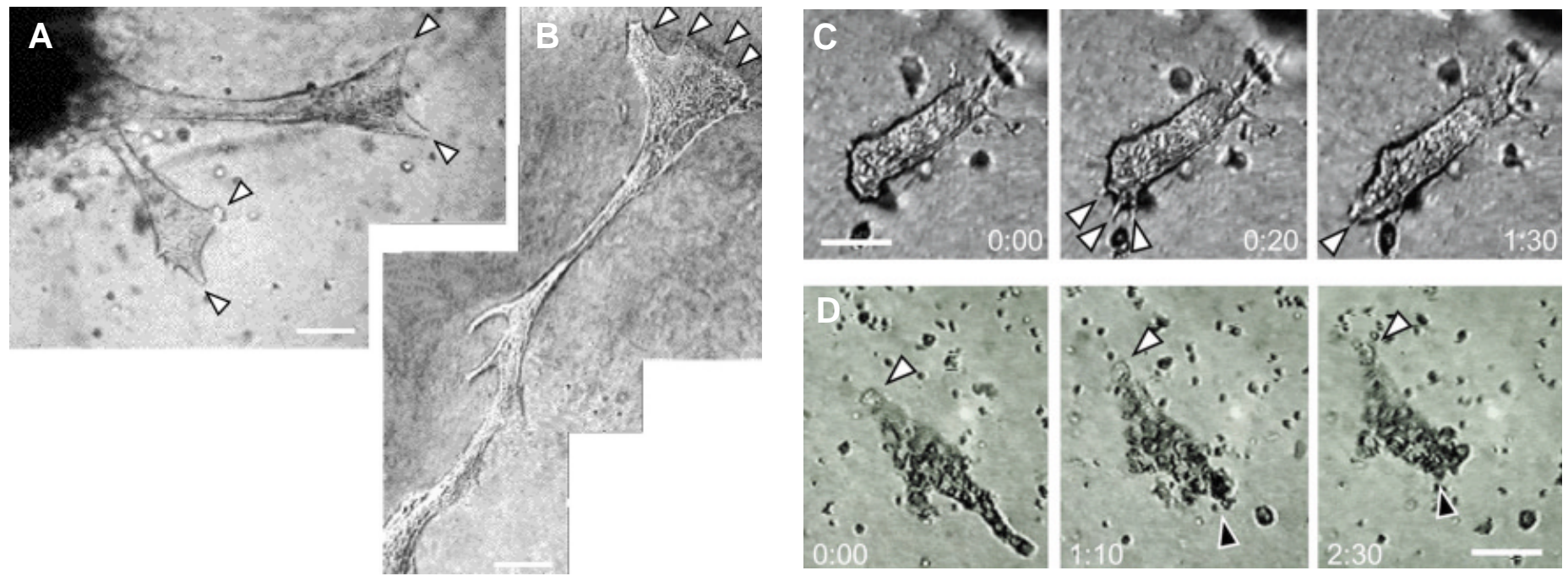

Fig.1. Morphological variants of collective cell migration in 3D collagen lattices. (A) Culture of a lung tissue explant (histopathological diagnosis: fibrotic lung tissue) resulted in growth and emigration of multicellular smooth epithelial strands into the collagen matrix. In morphogenesis models, similar patterning results from branching morphogenesis. (B) Invasion of a solid cell strand from an oral mucosa explant (histopathological diagnosis: squamous cell carcinoma with metastasis into regionary lymph nodes). A broader cone-like leading front is observed, yet the collective maintains contact with the origin (in lower left corner, not shown). (C) Solid strand-like cluster detached from an oral squamous cell carcinoma explant via collective migration. The front of the group develops coordinated pseudopod extension from several cells (arrowheads) followed by de-novo expansion of a unified leading edge. (D) Detached sheet-like cluster from an invasive oral squamous cell carcinoma. One leading cell guides the group (white arrowheads), while rear retraction is executed by one or several cells (black arrowheads). In this sample, a large number of tumor-infiltrating leukocytes emigrated from the tissue explant is additionally present. Bars, $100 \mu \mathrm{m}(\mathrm{A}-\mathrm{C}), 80 \mu \mathrm{m}(\mathrm{C})$. Time is indicated in h:min.

also cell strands, chains and clusters may emigrate from the cell compartment into the matrix (Fig. 1). The source material stems either from cell clumps (spheroids) obtained from in vitroculture or tissue explants. Depending on the cell type and resulting patterning, 3D invasion assays support the invasion of tumor cell clusters from cancer explants (Friedl et al. 1995), branching morphogenesis from explanted embryonic glandular tissue (O'Brien et al. 2002), or vascular sprouting from endothelial cell spheroids or aortic rings (Korff and Augustin 1999).

\section{In vivo models}

In vivo imaging of collective migration dynamics is predominantly monitored in transparent embryonic tissue, such as embryos of the chick, Drosophila, or Xenopus. Collective migration is seen as the invagination of germ ring cells into the embryonic shield during gastrulation in Fundulus (Trinkaus et al. 1992), the closure of the dorsal neural tube in Xenopus (Keller 2002), the migration of clustered cells in the developing ovary of Drosophila(Montell 1999) and the chain migration of neural precursor cells or endothelial cells. Collective tumor invasion can further be monitored in the chick chorioalantoic membrane assay (Easty 1974).

\section{Imaging}

In both, in vitro or in vivo models, the most direct access to the dynamics of migration and patterning is provided by time-lapse imaging, either by serial photography of the same region or timelapse video and digital microscopy (Hilfer et al. 1990, Friedl and Brocker 2004). For in vivo imaging in light-scattering tissues, the specification of the migrating cell-type and contrast towards the non-migrating background may require the use of fluorescent cells (e.g. expressing green-fluorescent protein) and imaging by confocal or multi-photon microscopy (Cooper and D'Amico 1996).

Several other widely used migration assays, such as filter invasion assays, the non-confluent culture of previously dispersed and individualized cells on 2D substrata or within 3D extracellular matrix bear single cell patterns and migration, not, however, collective cell movement.

\section{Basic mechanisms of collective migration}

For single cell migration, the forces that drive cell movement reside in cytoskeletal dynamics that are transferred to the extracellular scaffold via adhesion receptors. These have been classified as a cyclic 5-step process (Lauffenburger and Horwitz 1996, Friedl and Wolf 2003, Friedl 2004). Initial cell polarization is caused by intracellular actin polymerization to cytoplasmic filaments followed by the extension of ruffles or a leading pseudopod (step 1). Once this protruding cell extension touches ECM ligands, adhesion receptors of the $\beta 1$ and $\beta 3$ integrin families become engaged, cluster, attach to the substrate and recruit cytoplasmic adaptor and signaling proteins thereby connecting to actin filaments (step 2). The resulting local interaction regions are multifocal, in some cells defined as focal adhesions or focal contacts. By not fully understood mechanisms, surface proteases, such as MT1-MMP and UPA/UPAR are recruited to execute local proteolysis towards bordering ECM molecules and other proteins. Pericellular breakdown of matrix molecules is thought to provide space for the forward expanding cell body to penetrate extracellular tissue scaffolds (step 3). During or shortly after integrin-ligand binding, actin filaments engage with adaptor as well as crosslinking and contractile proteins, such as myosin II, which stabilize 
as well as contract the actin polymers (step 4). The shortening of membrane-tethered actin filaments results in local cell contraction, i.e. the retraction and forward gliding of the posterior cell pole and movement of the cell body including nucleus towards the leading edge (step 5). These five steps provide an adaptive and dynamic framework in most if not all cells studied to date, yet they may undergo cell type-specific modification dependent on the inherent molecular repertoire and the type of cell-cell junctions.

In collective migration, steps 1-4 of the migration cycle are retained, however the mode of rear retraction and forward gliding (step 5) contains an important modification. As in individual cells, collectively moving groups develop cytoskeletal dynamics at the leading edge to establish contact to the substrate. This results in multicellular outward ruffling at substrate binding sites and the generation of traction (Kolega 1981, Davis and Camarillo 1995). Because polarized cell-matrix interaction and force generation occur at the "free" pole of the cell mass only, a unipolar leading edge or lamella is generated (Fig. 1 A-C, white arrowheads).

If the moving cell bodies of leading cells remain connected to other cells by cell-cell junctions that are not abandoned upon rear retraction, trailing edge gliding drags the neighbour cells along the emerging migration track. The trailing edge, hence, exerts force towards both, cell matrix as well as cell-cell junctions. It is very likely, that active retraction via myosin or the release of adhesive bonds towards the substrate are involved here, yet the maintenance of cell-cell junctions transfers the direction of the net migration vector on the following cell group (Kolega 1981, Friedl et al. 1995). Single cell tracking of migrating cell clusters indicates that cells at different locations quite precisely retain their position within the group (Hegerfeldt et al. 2002). Movement of the group, hence, occurs without disturbing its inner architecture. In migrating clusters, trailing edge retraction is a collective process that simultaneously involves several cells (Fig. 1D, black arrowheads). Together, leading edge extension and force generation as well as rear retraction are shared functions among cells that are coupled with each other. Thereby, the traction-generating subset is distinct from those cells that become passively dragged and again from the cells that execute rear retraction, suggesting that functional differentiation is maintained among different sets of cells to maintain front-rear asymmetry in the group.

Different morphological patterns are obtained by this principal mechanism. Migrating cell collectives are frequently arranged as 2D sheets, like an epithelial layer migrating across substrate (Grose et al. 2002) or 3D solid strands (Fig. 1 A,B) develop, as in neural crest migration (Jacques et al. 1998). Alternatively, centrally hollow tubular structures represent tubulogenesis, vessel sprouting, branching morphogenesis, or gland formation (O'Brian et al., 2002). While cells of the leading edge engage in cell-ECM interactions and proteolytic ECM remodeling, the emerging matrix defect is then collectively filled by following cells and no apparent trailing edge is developed. This requires that cells are either recruited by forward gliding into the extending strand or that cell division compensates for the growing spatial requirements. If the group detaches from the origin, isolated clusters or cohorts are obtained (Fig. 1 C,D).

\section{Collective migration in morphogenesis and repair}

In morphogenesis, many developmental steps result from collective migration. Examples are the morphogenic movement of cells in the inner blastocyst (Trinkaus 1992); epithelial sprouts and developing ducts (branching morphogenesis) (Zegers et al. 2003); the migration of border cells (i.e. precursor oocytes) through the cell-rich scaffold of the early ovary in Drosophila (Montell 1999); and the movement of epithelial cells at the rim of the optic and the invaginating thyroid placode (Hilfer et al. 1990). A special and more complex example of collective migration is the collective or 'mass' movement, as seen during the converging extension of the vertebrate embryo, such as in Xenopus (Keller 2002, Tahinci and Symes 2003) and the closure of dorsal surface in the Drosophila embryo (Hutson et al. 2003). Besides collective migration, these 'movements' additionally comprise barely understood supracellular forces, that position and remould the shape and location of entire tissues, i.e. by extension and contraction of entire body regions and the folding of cell and matrix sheets (Hutson et al. 2003). These complex movements contain active and significant passive translocation mechanisms for cells and, hence, share similarities and some differences to collective migration in other models. However, the conclusive classification of migration processes in different morphogenic models remains to be established.

In tissue repair, similar to morphogenesis, collective migration is seen in vascular sprouts penetrating provisional fibrinrich wound matrix (Korff and Augustin 1999) or the horizontal migration of epithelial cell sheets across 2D substrates, such as the gut mucosa epithelium upon self-renewal or keratinocytes migrating across provisional wound matrix (Grose et al. 2002).
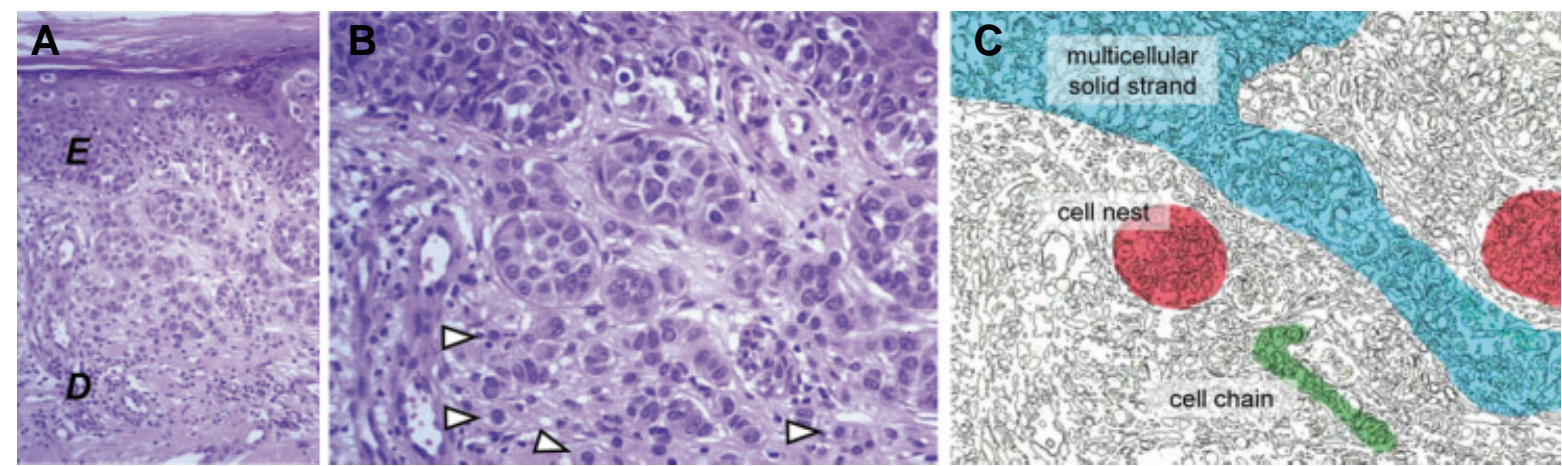

Fig. 2. Collective invasion patterns in primary melanoma. (A) Histopathological overview, (B) detail and (C) classification of invasion patterns of a cutaneous melanoma that had invaded into the mid reticular dermis. Besidesafewscattered individual tumor cells (arrowheads), multicellular solid stands as well as single cell chains ('Indian files') of connected melanoma cells have invaded into the dermal stroma. Multicellular tumor cell 'nests' (clusters) arguably represent cross-sectioned strands (C). E, epidermis, D, dermis. H\&E staining. 


\section{Collective migration in cancer}

Collective-cell movement is a putative mechanism for invasion and metastasis in not fully dedifferentiated tumors, among them epithelial cancers of high and intermediate differentiation grade (lobular breast cancer, epithelial prostate cancer, large-cell lung cancer) (Bell and Waizbard 1986, Page et al. 1987, de Castro et al. 2000), melanoma (Day et al. 1981) (Fig. 2) and rhabdomyosarcoma (Friedl et al. 1995). In highly differentiated epithelial cancer, tubular or glandular structures may be retained in the invading zone whereas, with the loss of apical-basal polarity and dedifferentiation, amorphous cell strands and masses that lack an inner lumen extend within the tissue.

Two morphological and functional variants of collective migration have been described in tumors in vivo (Fig. 2). The first results from protruding sheets and strands that maintain contact with the primary site, yet generate local invasion. These characteristics are histologically detectable in invasive epithelial cancer such as oral squamous-cell carcinoma and mammary carcinoma (Bell and Waizbard 1986, Page et al. 1987), colon carcinoma (Nabeshima etal. 1999), melanoma (Fig. 2), basal cell carcinoma and others. The second shows detached cell clusters or cell files. Groups of cells, histologically seen as 'nests', detach from their origin and frequently extend along interstitial tissue gaps and paths of least resistance, as well as along perineural structures, as seen in epithelial cancer and melanoma (Fig. 2) (Day et al. 1981, Ackerman 1984).

In the course of tumor progression, such cell collectives can be detected at any stage of metastasis. Tumour clusters enter lymphyatic vessels (Byers et al. 1995, Hashizume et al. 1996, Madhavan et al. 2001) and can be isolated from peripheral blood (Brandt et al. 1996). The dissemination of cell collectives likely has an impact on the mechanism and efficiency of metastasis towards secondary sites. B16 melanoma cells injected into the tail vein as small clusters (4-5 cells/clump) generate three-fold higher numbers of lung metastases compared to single injected cells (Fidler 1973). The collective dissemination route might thus not only support the invasion of an increased cell number per unit, but also the embolic route of metastasis formation and thereby increase the probability of tumor cell survival in tissues and vessels.

\section{Molecular mechanisms controlling collective migration}

The present knowledge on the molecular mechanisms of collective migration is incomplete and often indirect, due to a lack of standardized experimental models. For collective migration in stromal tissues, several independent lines of research suggest that integrin-mediated adhesion and force generation are coordinated with polarized cytoskeletal activity and protease activity. These functions become integrated and coordinated by several sets of cell-cell adhesion receptors and, most likely, intercellular communication.

\section{Cell-substrate interactions}

As in other migration processes, integrins of the $\beta 1$ and $\beta 3$ families become engaged and cluster at ruffling edges at free margins of collectively moving cell groups, both in $2 \mathrm{D}$ and $3 \mathrm{D}$ migration models (Fig. 3). The importance of integrins of the $\beta 1$ family in providing attachment and dynamic force generation was shown for neoplastic cancer cell clusters (Nabeshima et al. 2000, Hegerfeldt et al. 2002) (Fig. 3B), the convergent extension in Xenopus (Marsden and DeSimone 2003) and the development of solid cell strands in neuronal precursor cells from neurospheres (Jacques et al. 1998). While the leading cells generate actin and integrin-mediated traction, a linear cortical actin network extends along cell-cell junctions into deeper regions of the collective, suggesting a function of cortical actin in sustaining collective integrity (Davis and Camarillo 1995, Hegerfeldt et al. 2002, Sweeney et al. 2003). Collective movements of keratinocytes, neuronal precursor cells and neoplastic clusters are hence sensitive to integrin antagonists, which near-to-completely block cell 


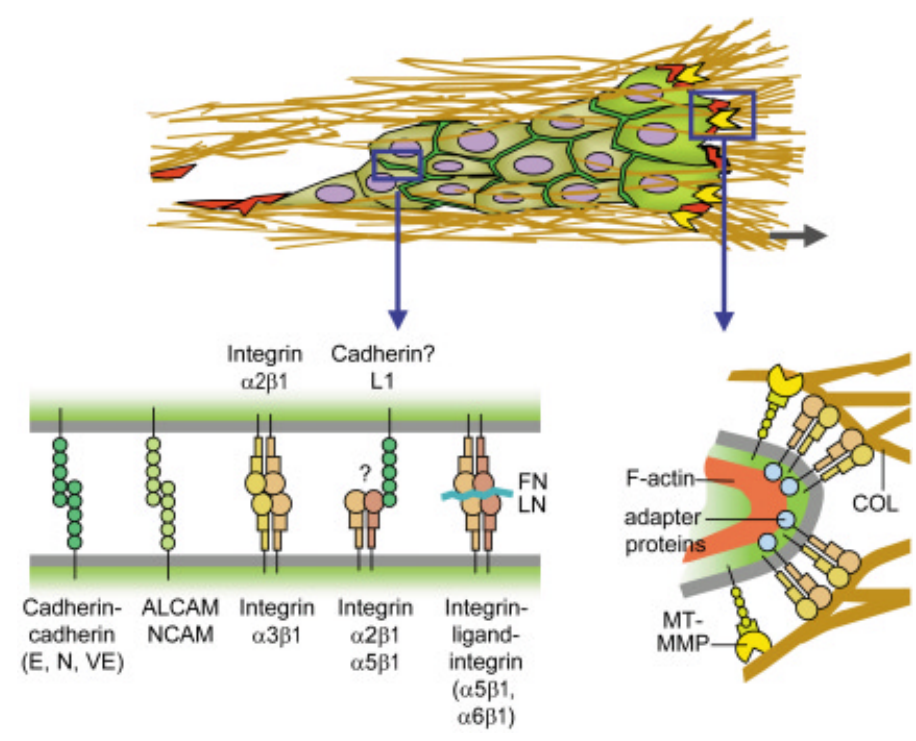

Fig. 4. Molecular principles involved in collective invasion. (A) Multicellular group migrating via adhesion and traction executed by several cells at the leading edge that are coupled to the other cells by cohesive forces. (B) Cell-cell adhesion can be provided by members of the cadherin family, other members of the immunoglobulin superfamily (e.g. NCAM, ALCAM) as well as heterophilic integrin-mediated interactions. (C) The leading edge generates traction via actin-mediated ruffling and pseudopod dynamics, integrin-mediated adhesion and recruitment of surface proteases, most notably of the MT-MMP family. The diagram represents a summary of different concepts from both, neoplastic and non-neoplastic models. In different cell types and environmental models, different combinations of adhesion receptors and proteases may be involved. Abbreviations: FN, fibronectin; $L N$, laminin.

traction and collective migration ( Jacques et al. 1998, Klinowska et al. 1999, Grose et al. 2002, Hegerfeldt et al. 2002).

Although little is known about intracellular regulation of integrin function in collective migration, signaling cascades known from single cell migration are likely to be retained. As one example, Rac is an important cytoplasmic Rho GTPase that controls actin dynamics in pseudopods, including adhesion and deadhesion. As in single cell movement, the expression of Rac is critical for collective migration of border cells in the Drosophila ovary (Montell 1999) and the convergent extension during Xenopus gastrulation (Tahinci and Symes 2003).

Migrating cell collectives develop preferential protease expression and engagement in a subset of cells at the leading edge. In adenocarcinoma clusters, cells at the leading margin show the highest capacity for proteolytic ECM remodeling via MT1-MMP and MMP-2 upregulation and redistribution (Nabeshima et al. 2000). This is consistent with preferential MMP function and substrate remodeling in vascular cell sprouting and branching morphogenesis (Hotary et al. 2002). Putatively because the proteolytic degradation of extracellular matrix provides space for the expanding size of cell strands and groups, collective migration is highly succeptible to protease inhibitors, as shown for kidney epithelial cells (Montesano et al. 1991), myoblast collectives (El Fahime et al. 2000), branching morphogenesis (Simian et al. 2001) and angiogenesis (Hiraoka et al. 1998, Collen et al. 2003).
Although polarized integrin and protease redistribution to substrate are established processes in polarized single cell and collective cell migration, likewise, it remains unclear by which mechanisms integrins and proteases become differentially expressed and/or engaged in only a certain cellular subset within cell groups (compare polar staining for $\beta 1$ integrin in Fig. 3 ).

\section{Cell-cell interactions}

In epithelial cancer and melanoma samples, homotypic cellcell interactions within multicellular strands and sheets have been shown to contain cadherins (E-, N-, P-, VE-cadherin and cadherin11; Fig. 3A) and other members of the immunoglobulin family of adhesion receptors (e.g. NCAM, ALCAM) (Bach et al. 1998, Silye et al. 1998, Carmeliet et al. 1999, Hsu et al. 2000, van Kempen et al. 2000, Li 2001), all of which are known to mediate homophilic receptor binding between cells (Fig. 4B). Likewise, clustered border cells in the Drosophila ovary are connected by an Ecadherin homolog (Niewiadomska et al. 1999). Several lines of evidence suggest that $\beta 1$ integrins, most notably $\alpha 2 \beta 1, \alpha 3 \beta 1$ and $\alpha 5 \beta 1$, can further maintain cell-cell adhesion in epithelial cells by direct and indirect mechanisms (Larjava et al. 1990, Whittard and Akiyama 2001, Whittard et al. 2002, Robinson et al. 2003) (Fig. 4B). Additional mechanisms that provide mechanical contact between cells in collectives are desmosomal proteins, as seen in invasive squamous cell carcinoma nests in vivo (Kurzen 2003); mature tight junctions and desmosomes in HeLa cell clusters in vitro(Brauner 1990); the heterophilic interaction of $L 1$, a neuronal adhesion molecule, with $\alpha 5 \beta 1$ integrin in different cell types (Silletti et al. 2000); and, arguably, $\alpha 2 \beta 1$ integrin binding to $\mathrm{E}$ cadherin (Whittard et al. 2002).

The generation and maintenance of front-rear asymmetry clearly requires specific mechanisms of cell-cell communication, that permit cytoskeletal dynamics at the leading edge while silencing other regions of the collective. Such mechanisms could be mediated by gap junctional cell-cell communication, as indicated by increased collective invasivenes of HeLa cells after the overexpression of Connexin43, 40 or 31 (Graeber and Hulser 1998, Hsu et al. 2000). Consequently, increasing cell-cell adhesion and communication converts dispersed cells towards collective migration and vice versa. As one example, trefoil peptides are known mediators of cell-cell adhesion and simultaneously induce motogenic responses in epithelial cells during epithelial repair in epidermis and gut mucosa. In mammary adenocarcinoma cells cultured in 3D collagen lattices, trefoil peptides convert previously single cells to efficiently invasive collective strands and sheets (Williams et al. 1996). These and other regulators of epithelial regeneration might maintain collective cell behavior by stabilizing cell-cell interactions. On the other hand, reducing cell-cell adhesion by blocking cadherins or integrins causes the disruption of cell collectives towards individual cell migration.

\section{Plasticity of collective migration}

Interference with molecules that maintain or regulate collective cell behaviour can lead to a dissociation reaction that is followed by single cell detachment. Depending on the type of single cell migration obtained after the dissociation reaction, two modes of conversion are presently known, the epithelial-mesenchymal transition and the collective-amoeboid transition. 


\section{Epithelial-Mesenchymal Transition}

During progressive dedifferentiation in epithelial cancer, the conversion from multicellular growth and invasion towards mesenchymal single cell migration is termed the epithelial-mesenchymal transition (EMT) (Thiery 2002)(and refs. therein). The major mechanism is the loss of cell-cell junctions provided by different pathways. These include reduced cadherin expression, loss-offunction mutations in cadherin and catenin-signaling pathways and deregulated function of proteases leading to degradation of cadherins and other cell-cell adhesion molecules (Sternlicht $e t a l$. 1999). If integrin and protease functions as well as promigratory signaling remain undiminished, detaching cells then perform a mesenchymal-type single cell migration (Lochter et al. 1999, Thiery 2002). In vivo, EMT corresponds to the loss of differentiated epithelial morphology, first in regions, later in the complete lesion towards a sarcomatous stromal phenotype (Thiery 2002). In morphogenesis, an EMT-like transition is the exit of neuronal cells from the ventricular epithelium to form the neocortex.

Phase 1: Collective movement

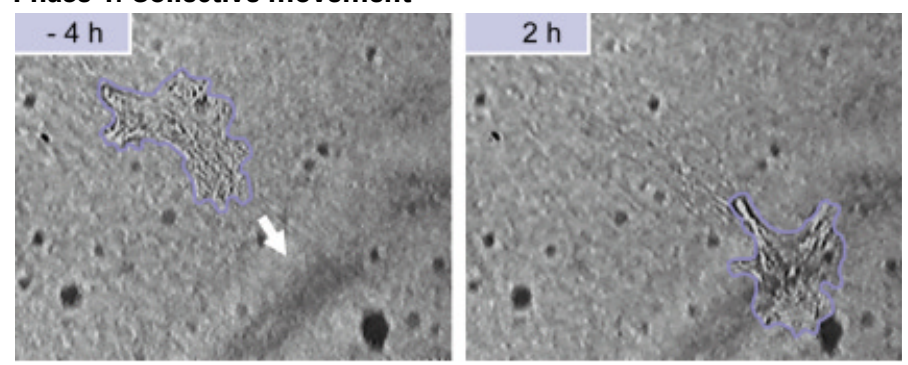

Phase 2: Loss of front-rear assymetry

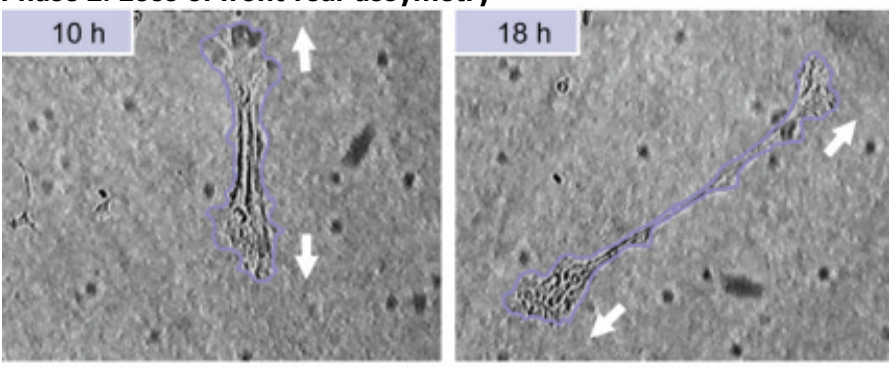

Phase 3: Collective-amoeboid transition

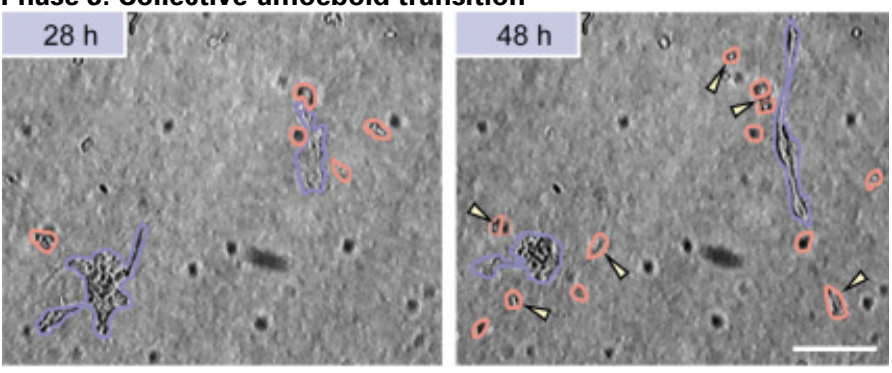

Fig. 5. Collective-amoeboid transition after addition of adhesionperturbing anti- $\beta 1$ integrin antibody to a cluster from a primary melanoma explant. Different stages are (1) initial migration of a multicellular sheet (blue outline), (2) loss of front-rear asymmetry and the development of two opposing leading edges approx. 8 hours after addition of the antibody. (3) The loss of collective migration was followed by detachment of individual cells that utilize a roundish amoeboid migration mode (red outline). Antibody was added at time point ' $O$ '. For details and related movie sequences see ref. (Hegerfeldt et al. 2002). Bar, $100 \mu \mathrm{m}$.

\section{Collective-amoeboid transition}

Similar to EMT, the transition from collective invasion to amoeboid single cell crawling is obtained if cell-cell and cell-ECM interactions are simultaneously weakened (Fig. 5). In multicellular clusters emigrating from melanoma explants, the inhibition of $\beta 1$ integrins by adhesion-perturbing antibody abrogates collective movement yet induces the detachment of individual amoeboid cells from the collective (Hegerfeldt et al. 2002) (Fig. 5). Detached cells then continue to move via amoeboid shape change, cell constriction at narrow regions of the extracellular tissue and maintain an $\beta 1$ integrin-independent migration type, similar to the integrin- and protease-independent migration of amoeboid T lymphocytes in 3D collagen lattices (Hegerfeldt et al. 2002, Wolf et al. 2003). While the molecular mechanism for dispersing cell collectives towards amoeboid single cells requires further investigation, these observations suggest that individual and collective migration modes represent temporary states that can interchange depending on the cells' internal molecular repertoire and environmental factors.

\section{Conclusions}

Collective migration supports important and ubiquitous translocation strategies for cells in diverse tissue environments. Collective processes simultaneously integrate cell movement and remodelling of tissue structures while anatomic patterns become established and remain intact within the group. In embryological development, tissue repair and cancer invasion, collective migration appears to follow some common principles, that require more in depth exploration for different sets of adhesion receptors, proteases, cytoskeletal regulators as well as extracellualar motogenic factors. In neoplastic growth and invasion, the formation of ducts, glands, or epithelial sheets seem to represent incomplete, abortive variants of those morphogenic processes.

For the progression of cancer disease, it is obvious that several advantages might reside in collective processes over disseminating individual cells. The large cell mass could produce high autocrine concentrations of promigratory factors and matrix proteases and protect inner cells from immunological assault through lymphocytes and natural-killer cells. Because heterogeneous sets of cells move as one functional unit, cells of different clonal origin or different biological abilities are likely to function together ('mixed clone' behavior). For example, more migratory cells can promote the invasion of less mobile or even immobile cells in experimental border cell migration in the Drosophila ovary (Liu and Montell 1999). Once cancer cell collectives have reached the lymph or blood stream, they might be more efficient in embolizing small vessels and survive in even hostile environment to establish metastasis (Fidler 1973).

Because of the molecular and functional differences between individual and collective cell behavior, future in vitro and in vivo models need to more precisely reflect those patterns, as seen in human disease in histological tissue sections. Cell lines will require to be classified not only from their tumor source, previous histological pattern and metastatic ability, but also by the type of pattern they re-establish after ortotopic implantation in small animal models. Thus, presently favoured concepts on the predominant contribution of single cells to invasion and metastasis formation might require further refinement. 


\section{Acknowledgements}

We would like to express our thanks to Eva-B. Bröcker and Christian Rose and for continuous supply and expert histopathological examination of tumor samples.

\section{References}

ACKERMAN, A.B. 1984. Malignant melanoma. pp.147-158 in A. B. ACKERMAN and A. RAGAZ, eds. Masson Publ. USA, New York.

BACH, T. L., BARSIGIAN, C., CHALUPOWICZ, D. G., BUSLER, D., YAEN, C.H., GRANT, D. S. and MARTINEZ, J. 1998. VE-Cadherin mediates endothelial cell capillary tube formation in fibrin and collagen gels. Exp Cell Res 238: 324-34.

BARFURTH, D. 1891. Zur Regeneration der Gewebe. Arch. Mikroskop. Anat. EntwMech. 37: 406-491.

BELL, C. D. and WAIZBARD, E. 1986. Variability of cell size in primary and metastatic human breast carcinoma. Invasion Metastasis 6: 11-20.

BRANDT, B., JUNKER, R., GRIWATZ, C., HEIDL, S., BRINKMANN, O., SEMJONOW, A., ASSMANN, G. and ZANKER, K. S. 1996. Isolation of prostatederived single cells and cell clusters from human peripheral blood. Cancer Res 56: 4556-4561.

BRAUNER, T. H., HULSER, D.F. 1990. Tumor cell invasion and gap junctional communication. Invasion Metastasis 10: 31-48.

BYERS, S. W., SOMMERS, C.L., HOXTER, B., MERCURIO, A.M. and TOZEREN, A. 1995. Role of E-cadherin in the response of tumor cell aggregates to lymphatic, venous and arterial flow: measurement of cell-cell adhesion strength. J.Cell Sci. 108: 2053-2064.

CARMELIET, P., LAMPUGNANI, M.G., MOONS, L., BREVIARIO, F., COMPERNOLLE, V., BONO, F., BALCONI, G., SPAGNUOLO, R., OOSTUYSE, B., DEWERCHIN, M., ZANETTI, A., ANGELLILO, A., MATTOT, V., NUYENS, D., LUTGENS, E., CLOTMAN, F., DE RUITER, M.C., GITTENBERGER-DE GROOT, A., POELMANN, R., LUPU, F., HERBERT, J. M., COLLEN, D. and DEJANA, E. 1999. Targeted deficiency or cytosolic truncation of the VEcadherin gene in mice impairs VEGF-mediated endothelial survival and angiogenesis. Cel/98: 147-57.

COLLEN, A., HANEMAAIJER, R., LUPU, F., QUAX, P. H., VAN LENT, N., GRIMBERGEN, J., PETERS, E., KOOLWIJK, P. and VAN, V, H. 2003. Membrane-type matrix metalloproteinase-mediated angiogenesis in a fibrin-collagen matrix. Blood 101: 1810-1817.

COOPER, M. S. and D'AMICO, L. A. 1996. A cluster of noninvoluting endocytic cells at the margin of the zebrafish blastoderm marks the site of embryonic shield formation. Dev.Biol. 180: 184-198.

DAVIS, G.E. and CAMARILLO, C.W. 1995. Regulation of endothelial cell morphogenesis by integrins, mechanical forces and matrix guidance pathways. Exp.Ce// Res. 216: 113-123.

DAY, C. L., Jr., HARRIST, T. J., GORSTEIN, F., SOBER, A. J., LEW, R. A. FRIEDMAN, R. J., PASTERNACK, B. S., KOPF, A. W., FITZPATRICK, T. B. and MIHM, Jr., M. C. 1981. Malignant melanoma. Prognostic significance of "microscopic satellites" in the reticular dermis and subcutaneous fat. Ann. Surg. 194: 108-12.

de castro, J., Gamallo, C., palacios, J., moreno-bueno, G., RODRIGUEZ, N., FELIU, J. and GONZALEZ-BARON, M. 2000. $\beta$-catenin expression pattern in primary oesophageal squamous cell carcinoma. Relationship with clinicopathologic features and clinical outcome. Virchows Arch. 437: 599-604.

DEHAAN, R. L. 1963. Migration patterns of the precardiac mesoderm in the early chick embryo. Exp. Cell Res. 29: 544-560.

EASTY, D. M. E. and EASTY, G.C. 1974. Measurement of the ability of cells to infiltrate normal tissues in vitro. Br.J.Cancer29: 36-48.

EL FAHIMA, E., TORRENTE, Y., CARON, N. J., BRESOLIN, M. D. and TREMBLAY, J. P. 2000. In vivo migration of transplanted myoblasts requires matrix metalloproteinase activity. Exp.Cell Res 258: 279-287.

EYCLESHYMER, A. C. 1907. The closing of wounds in the larval Necturus. Am.J.Anat. 1: 317-325.

FIDLER, I. J. 1973. The relationship of embolic homogeneity, number, size and viability to the incidence of experimental metastasis. Eur. J. Cancer9: 223-237.
FRIEDL, P., NOBLE, P. B., WALTON, P. A., LAIRD, D. E., CHAUVIN, P. J., TABAH, R. J., BLACK, M. and ZANKER, K. S. 1995. Migration of coordinated cell clusters in mesenchymal and epithelial cancer explants in vitro. Cancer Res. 55: 4557-4560.

FRIEDL, P. and WOLF, K. 2003. Tumour-cell invasion and migration: diversity and escape mechanisms. Nat Rev Cancer 3: 362-374.

FRIEDL, P. 2004. Prespecification and plasticity: shifting mechanisms of cell migration. Curr. Opin. Cell Biol. 16: 14-23.

FRIEDL, P. and BROCKER, E. B. 2004. Reconstructing leukocyte migration in 3D extracellular matrix by time-lapse videomicroscopy and computer-assisted tracking. Methods Mol. Biol. 239: 77-90.

GRAEBER, S. H. and HULSER, D. F. 1998. Connexin transfection induces invasive properties in HeLa cells. Exp. Cell Res. 243: 142-149.

GROSE, R., HUTTER, C., BLOCH, W., THOREY, I., WATT, F. M., FASSLER, R, BRAKEBUSCH, C. and WERNER, S. 2002. A crucial role of $\beta 1$ integrins for keratinocyte migration in vitro and during cutaneous wound repair. Development 129: 2303-2315.

HASHIZUME, R., KOIZUMI, H., IHARA, A., OHTA, T. and UCHIKOSHI, T. 1996. Expression of $\beta$-catenin in normal breast tissue and breast carcinoma: a comparative study with epithelial cadherin and $\alpha$-catenin. Histopathology 29 : 139-146.

HEGERFELDT, Y., TUSCH, M., BROCKER, E. B. and FRIEDL, P. 2002. Collective cell movement in primary melanoma explants: plasticity of cell-cell interaction, $\beta 1$-integrin function and migration strategies. Cancer Res. 62: 2125-2130.

HILFER, S. R., MARRERO, L. and SHEFFIELD, J. B. 1990. Patterns of cell movement in early organ primordia of the chick embryo. Anat. Rec. 227: 508517.

HIRAOKA, N., ALLEN, E., APEL, I. J., GYETKO, M. R. and WEISS, S. J. 1998. Matrix metalloproteinases regulate neovascularization by acting as pericellular fibrinolysins. Cel/95: 365-377.

HOTARY, K. B., YANA, I., SABEH, F., LI, X. Y., HOLMBECK, K., BIRKEDALHANSEN, H., ALLEN, E. D., HIRAOKA, N. and WEISS, S. J. 2002. Matrix metalloproteinases (MMPs) regulate fibrin-invasive activity via MT1-MMPdependent and -independent processes. J. Exp. Med 195: 295-308.

HSU, M., ANDL, T., LI, G., MEINKOTH, J. L. and HERLYN, M. 2000. Cadherin repertoire determines partner-specific gap junctional communication during melanoma progression. J. Cell Sci. 113: 1535-1542.

HUTSON, M. S., TOKUTAKE, Y., CHANG, M. S., BLOOR, J. W., VENAKIDES, S., KIEHART, D. P. and EDWARDS, G. S. 2003. Forces for morphogenesis investigated with laser microsurgery and quantitative modeling. Science 300 : 145-9.

JACQUES, T. S., RELVAS, J. B., NISHIMURA, S., PYTELA, R., EDWARDS, G. M., STREULI, C. H. and FFRENCH-CONSTANT, C. 1998. Neural precursor cell chain migration and division are regulated through different $\beta 1$ integrins. Development 125: 3167-3177.

KELLER, R. 2002. Shaping the vertebrate body plan by polarized embryonic cell movements. Science 298: 1950-4.

KLINOWSKA, T. C., SORIANO, J. V., EDWARDS, G. M., OLIVER, J. M., VALENTIJN A. J., MONTESANO, R. and STREULI, C. H. 1999. Laminin and $\beta 1$ integrins are crucial for normal mammary gland development in the mouse. Dev. Biol. 215: 13-32.

KOLEGA, J. 1981. The movement of cell clusters in vitro: morphology and directionality. J.Cel/ Sci. 49:15-32: 15-32.

KOLEGA, J. S., SURE, M.S., CHEN, W.-T. and YOUNG, N.D. 1982. Rapid cellular translocation is related to close contacts formed between various cultured cells and their substrata. J. Cell Sci. 54: 23-34.

KORFF, T. and AUGUSTIN, H. G. 1999. Tensional forces in fibrillar extracellular matrices control directional capillary sprouting. J. Cell Sci. 112: 3249-3258.

KURZEN, H. M., I. and HARTSCHUH, W. 2003. Expression of desmosomal proteins in squamous cell carcinomas of the skin. J. Cutan. Pathol. 30: 621-630.

LARJAVA, H., PELTONEN, J., AKIYAMA, S. K. and YAMADA, S. S. 1990. Nove function for $\beta 1$ integrins in keratinocyte cell-cell interactions. J. Cell Biol. 110: 803-815.

LAUFFENBURGER, D. A. and HORWITZ, A. F. 1996. Cell migration: a physically integrated molecular process. Cel/84: 359-369. 
LI, G. S., SATYAMOORTHY, K. and HERLYN, M. 2001. N-cadherin-mediated intercellular interactions promote survival and migration of melanoma cells. Cancer Res. 61: 3819-3825.

LIU, Y. and MONTELL, D. J. 1999. Identification of mutations that cause cell migration defects in mosaic clones. Development 126: 1869-1878.

LOCHTER, A., NAVRE, M., WERB, Z. and BISSELL, M. J. 1999. $\alpha 1$ and $\alpha 2$ integrins mediate invasive activity of mouse mammary carcinoma cells through regulation of stromelysin-1 expression. Mol. Biol. Cel/10: 271-282.

MADHAVAN, M., SRINIVAS, P., ABRAHAM, E., AHMED, I., MATHEW, A., VIJAYALEKSHMI, N. R. and BATARAM, P. 2001. Cadherins as predictive markers of nodal metastasis in breast cancer. Mod. Pathol. 14: 423-427.

MARSDEN, M. and DESIMONE, D. W. 2003. Integrin-ECM interactions regulate cadherin-dependent cell adhesion and are required for convergent extension in Xenopus. Curr. Biol. 13: 1182-1191.

MONTELL, D. J. 1999. Developmental regulation of cell migration. Insight from a genetic approach in Drosophila. Cell Biochem. Biophys. 31: 219-229.

MONTELL, D. J., RORTH, P. and SPRADLING, A. C. 1992. slow border cells, a locus required for a developmentally regulated cell migration during oogenesis, encodes Drosophila C/EBP. Cel/71: 51-62.

MONTESANO, R., SCHALLER, G. and ORCI, L. 1991. Induction of epithelial tubular morphogenesis in vitro by fibroblast-derived soluble factors. Cel/ 66: 697-711.

NABESHIMA, K., INOUE, T., SHIMANO, Y., KATAOKA, H. and KOONO, M. 1999. Cohort migration of carcinoma cells: differentiated colorectal carcinoma cells move as coherent cell clusters or sheets. Histol. Histopathol. 14: 1183-1197.

NABESHIMA, K., INOUE, T., SHIMAO, Y., OKADA, Y., ITOH, Y., SEIKI, M. and KOONO, M. 2000. Front-cell-specific expression of membrane-type 1 matrix metalloproteinase and gelatinase A during cohort migration of colon carcinoma cells induced by hepatocyte growth factor/scatter factor. CancerRes. 60: 33643369 .

NABESHIMA, K., MORIYAMA, T., ASADA, Y., KOMADA, N., INOUE, T., KATAOKA, H., SUMIYASHI, A. and KOONO, M. 1995. Ultrastructural study of TPA-induced cell motility: human well-differentiated rectal adenocarcinoma cells move as coherent sheets via localized modulation of cell-cell adhesion. Clin. Exp. Metastasis 13: 499-508.

NABESHIMA, K., SHIMAO, Y., INOUE, T., ITOH, H., KATAOKA, H. and KOONO, M. 1998. Hepatocyte growth factor/scatter factor induces not only scattering but also cohort migration of human colorectal-adenocarcinoma cells. Int. J. Cancer 78: 750-759.

NIEWIADOMSKA, P., GODT, D. and TEPASS, U. 1999. DE-Cadherin is required for intercellular motility during Drosophila oogenesis. J. Cel/ Biol. 144: 533-547.

NOBES, C. D. and HALL, A. 1999. Rho GTPases control polarity, protrusion and adhesion during cell movement. J.Cel/ Biol. 144: 1235-1244.

O'BRIEN, L. E., ZEGERS, M. M. and MOSTOV, K. E. 2002. Opinion: Building epithelial architecture: insights from three-dimensional culture models. Nat Rev. Mol. Cell. Biol. 3: 531-537.

PAGE, D. L., ANDERSON, T. and SAKAMOTO, G. 1987. Infiltrating carcinomas. major histological types. in PAGE, D. L. and ANDERSON, T. J., eds. Churchill Livingstone, New York, pp. 219-222.

PALSSON, E. and OTHMER, H. G. 2000. A model for individual and collective cell movement in Dictyostelium discoideum. Proc. Natl. Acad. Sci. USA 97: 1044810453.
ROBINSON, E. E., ZAZZALI, K. M., CORBETT, S. A. and FOTY, R. A. 2003. $\alpha 5 \beta 1$ integrin mediates strong tissue cohesion. J. Cell Sci. 116: 377-386.

SILLETTI, S., MEI, F., SHEPPARD, D. and MONTGOMERY, A. M. 2000. Plasminsensitive dibasic sequences in the third fibronectin-like domain of L1-cell adhesion molecule (CAM) facilitate homomultimerization and concomitant integrin recruitment. J. Cell Biol. 149: 1485-1502.

SILYE, R., KARAYIANNAKIS, A. J., SYRIGOS, K. N., POOLE, S., VAN NOORDEN, S., BATCHELOR, W., REGELE, H., SEGA, W., BOESMUELLER, H., KRAUSZ, T. and PIGNATELLI, M. 1998. E-cadherin/catenin complex in benign and malignant melanocytic lesions. J. Pathol. 186: 350-355.

SIMIAN, M., HIRAI, Y., NAVRE, M., WERB, Z., LOCHTER, A. and BISSELL, M. J. 2001 The interplay of matrix metalloproteinases, morphogens and growth factors is necessary for branching of mammary epithelial cells. Development 128: $3117-$ 3131.

STERNLICHT, M. D., LOCHTER, A., SYMPSON, C. J., HUEY, B., ROUGIER, J. P GRAY, J. W., PINKEL, D., BISSELL, M. J. and WERB, Z. 1999. The stromal proteinase MMP3/stromelysin-1 promotes mammary carcinogenesis. Cel/98: 137146

SWEENEY, S. M., DILULLO, G., SLATER, S. J., MARTINEZ, J., IOZZO, R. V., LAUERFIELDS, J. L., FIELDS, G. B. and SAN ANTONIO, J. D. 2003. Angiogenesis in collagen I requires $\alpha 2 \beta 1$ ligation of a GFP ${ }^{\star}$ GER sequence and possibly p38 MAPK activation and focal adhesion disassembly. J. Biol. Chem. 278: 30516-30524.

TAHINCI, E. and SYMES, K. 2003. Distinct functions of Rho and Rac are required for convergent extension during Xenopus gastrulation. Dev. Biol. 259: 318-35.

THIERY, J. P. 2002. Epithelial-mesenchymal transitions in tumour progression. Nat Rev. Cancer2: 442-454.

TRINKAUS, J. P. 1992. The midblastula transition, the YSL transition and the onset of gastrulation in Fundulus. Dev. Suppl: 75-80.

TRINKAUS, J. P., TRINKAUS, M. and FINK, R.D. 1992. On the convergent cell movements of gastrulation in Fundulus. J. Exp. Zool. 261: 40-61.

VAN KEMPEN, L. C., VAN DEN OORD, J. J., VAN MUIJEN, G. N., WEIDLE, U. H., BLOEMERS, H. P. and SWART, G. W. 2000. Activated leukocyte cell adhesion molecule/CD166, a marker of tumor progression in primary malignant melanoma of the skin. Am. J. Patho/156: 769-774.

VAUGHAN, R. B. and TRINKAUS, J. P. 1966. Movements of epithelial cell sheets in vitro. J. Cell Sci. 1: 407-413.

VIRCHOW, R. 1863. Ueber bewegliche thierische Zellen. Arch. Path. Anat. Physiol.28 237-240.

WHITTARD, J. D. and AKIYAMA, S. K. 2001. Activation of $\beta 1$ integrins induces cell-cell adhesion. Exp. Cell Res. 263: 65-76.

WHITTARD, J. D., CRAIG, S. E., MOULD, A. P., KOCH, A., PERTZ, O., ENGEL, J. and HUMPHRIES, M. J. 2002. E-cadherin is a ligand for integrin $\alpha 2 \beta 1$. Matrix Biol. 21 : 525-532.

WILLIAMS, R., STAMP, G. W., GILBERT, C., PIGNATELLI, M. and LALANI, E. N. 1996 pS2 transfection of murine adenocarcinoma cell line 410.4 enhances dispersed growth pattern in a 3-D collagen gel. J. Cell Sci. 109: 63-71.

WOLF, K., MULLER, R., BORGMANN, S., BROCKER, E. B. and FRIEDL, P. 2003 Amoeboid shape change and contact guidance: T-lymphocyte crawling through fibrillar collagen is independent of matrix remodeling by MMPs and other proteases. Blood 102: 3262-3269.

ZEGERS, M. M., O'BRIEN, L. E., YU, W., DATTA, A. and MOSTOV, K. E. 2003 Epithelial polarity and tubulogenesis in vitro. Trends Cell Biol. 13: 169-76. 